\title{
Türk Evi Pavyonu'nun Ulusal Bilincin Kökenleri Metni Üzerinden Okunması
}

\author{
Elif GELMEZ DEMIR ${ }^{1 *}$
}

Öz

Benedict Anderson, ilk kez 1983 tarihinde yayımlanan Hayali Cemaatler, Milliyetçiliğin Kökenleri ve Yayılması kitabında 19. ve 20. yüzyılda meydana gelen olaylar sonrasında ortaya çıkan, milliyetçilerin kadim topluluklar olarak tanımladığı, millet-ulus kavramını yeniden tanımlar. Anderson, "hayal edilen" bu kavramın yazılı ve sözlü iletişim ile hızla yayıldığına, metinlerinde dikkat çeker.

Türkiye'de, Erken Cumhuriyet Dönemine gelindiğinde ulusalcılık kavramı kurumlarda, sosyal ve siyasi hayatta kendine yer bulmuştur. Mimarlık da bu kavramdan beslenmiştir. Dönemin mimarları bu milliyetçi söylemleri ile dönemin mimari anlayışını etkilemişlerdir. Bu bağlamda incelenecek olan, Sedad Hakkı Eldem'in 1939 New York Fuarı için tasarladığı Türk Evi Pavyonu, mimarlık özelinde, ulusalcılık kavramını temsil eden bir yapı olması sebebi ile bu çalışmada incelenmek üzere seçilmiştir. Bu çalışmada, Anderson'un, Hayali Cemaatler: Milliyetçiliğin Kökenleri ve Yayılması adlı kitabında bir bölüm olan, Ulusal Bilincin Kökenleri metni referans alınarak, Sedad Hakkı Eldem'in kendi kaleminden 1939 New York Fuarı Türk Evi Pavyonunu anlattığı metin, Eldem'in Türk evi teorisini milli mimarlık bağlamında tartışan diğer metinlerle incelenecektir.

Anahtar Kelimeler: Milli Mimari, Milliyetçilik, Türk Evi, Tarih Yazımı

\section{Reading the Turkish House Pavilion through the Text of The Origins of National Consciousness}

\begin{abstract}
Benedict Anderson redefines the concept of nation, which emerged after the events that took place in the 19th and 20th centuries in the book Imagined Communities: Reflections on the Origin and Spread of Nationalism, published in 1983. Anderson states in his texts that this "imagined" concept is rapidly spreading through written and verbal communication.

In Turkey, the concept of nationalism in Early Republican institutions, social and political life has found its place. Architecture is also affected by this concept. Architects influenced the architectural understanding of the period with these nationalist discourses. The Turkish House Pavilion designed by Sedad Hakkı Eldem for the 1939 New York Fair, which will be analyzed in this context, was chosen to be examined in this study because it is a structure representing the concept of nationalism in terms of architecture. In this study, the text in which Sedad Hakkı Eldem narrated the 1939 New York Fair Turkish House Pavilion was analyzed with Anderson's Origins of National Consciousness text. It will be examined with other texts discussing Eldem's Turkish house theory in the context of national architecture.

Keywords: National Architecture, Nationalism, Turkish House, Historiography

\footnotetext{
${ }^{1}$ İstanbul Kültür Üniversitesi, Mimarlık Fakültesi, İç Mimarlık ve Çevre Tasarımı Bölümü, İstanbul

* Bu makale, Doç. Dr. Alev Erkmen Özhekim yürütücülüğünde, 2019-2020 Bahar Dönemi Yıldız Teknik Üniversitesi Mimarlık Tarihinde Yöntembilim dersi kapsamında hazırlanan ödev üzerinden geliştirilmiştir.

* Illgili yazar/Corresponding author: e.gelmez@iku.edu.tr

Gönderim Tarihi / Received Date: 17.10.2020

Kabul Tarihi / Accepted Date: 31.03.2021
} 


\section{Benedict Anderson'un Milliyetçilik Tanımı Üzerine}

Benedict Anderson ${ }^{1}$, Hayali Cemaatler Milliyetçiliği Kökenleri ve Yayılması kitabının ikinci baskısında kitabı yazma kararı almasındaki en büyük etkenin 1978-79 yıllarında yaşanan Çinhindi'deki savaş olduğunu söyler. Savaşın tarafları olan sosyalist rejimle yönetilen ülkelerin aynı zamanda milliyetçilik rejimini benimsemiş olması teorisi, yazarı bu kitabı yazmaya itmiştir (Anderson, 1983, s. 9). Milliyetçiliği tanımlayan diğer kuramcılar Avrupa'dan örneklerle bu kavramı açıklama yoluna giderken, Anderson kitabında farklı coğrafyalarda yaşanan olaylardan örnekler verir. Bu çeşitlilik, yazarı çağdaşlarından ayırmaktadır. Anderson'un hayatının büyük bir bölümünü Güney Asya'da geçirmiş olması, bunda büyük bir etkendir.

Anderson, ulus kavramını “...Ulus hayal edilmiş bir siyasal topluluktur - kendisine aynı zamanda hem egemenlik hem de sınırlılık içkin olacak şekilde hayal edilmiş bir cemaattir." tanımıyla açıklar. Yazara göre bu kavram hayal edilmiştir. Çünkü ulusu oluşturan ögelerin hiçbiri birbirini tanımaz ancak bu kavram zihinlerde bir topluluk olarak var olmaya devam eder. Birebir iletişimin mümkün olduğu, nüfusu az olan ilkel kabilelerde bu olgunun var olmasını ise bir istisna kabul eder (Anderson, 1983, s. 1213). Yazar teorisini, Ernest Renan'ın “... Ancak, bir ulusun özü tüm bireylerin ortak pek çok şeye sahip olmaları ve aynı zamanda hepsinin pek çok şeyi unutmuş olmasıdır" tanımı ve Ernest Gellner'in “...Milliyetçilik ulusların kendi öz-bilinçlerine uyanma süreci değildir; ulusların var olmadığı yerde onları icad eder.” tanımı ile destekler.

Milliyetçiliği ideolojik bir kavram olarak tanımlayanların aksine, Anderson bu kavramın hayali olmasına vurgu yapar. Diğer ideolojik olgulara göre teorik yanının oldukça eksik olması sebebiyle, her ideolojik görüşün kendine ait bir milliyetçilik tanımı vardır der (Sever, 2015, s. 51). Hobsbawmn da benzer şekilde milliyetin toplumsal bir değer olmasının sadece 'milli devlet' ilişkisi kurulduğunda mümkün olduğunu belirtir (Hobsbawm, 1995, s. 24). Milliyetçilik kavramı, faşizm, liberalizm gibi olguların değil, akrabalık, din gibi olguların paralelliğinde ilerler. Milliyetçiliğin dinden farklı olarak yayılmacı tavır sergilemediği söylenebilir. Hiç bir ırk diğer ırkların kendi uluslarına katılması için çaba sarf etmez. Örnek vermek gerekirse İslam inancındaki cihat anlayışına benzer bir inanış ya da tüm dinlerde olan misyonerlik faaliyetleri milliyetçiliğin özünde yoktur. Ancak milliyetçilik, kendi hedef kitlesine kendi milli bilincini yaymayı amaçlar.

Anderson'a göre ulaştırma yöntemlerinden biri milliyetçiliğin modern sembolü olan meçhul asker anıtlarıdır ${ }^{2}$ (Anderson, 1983, s. 22-23). Diğeri ise ortak geçmiş yaratmak. Yazar, Endonezya Başkanı'nın 350 yıldır sömürgecilik ile boğuştuğu yönündeki açıklamaları olmasına karşın, Endonezya kavramının 20. yüzyılda ortaya çıktığına dikkat çeker. Benzer şekilde Mustafa Kemal Atatürk'ün devlet bankalarının isimlerini Sümerbank ve Etibank olarak belirlemesini, Sümer ve Hititleri kendi atası olarak görmesi ve bu geçmişi benimsetme girişimi olarak nitelendirir (Anderson, 1983, s. 2526).

\footnotetext{
${ }^{1}$ İrlanda kökenli Benedict Anderson (1936-2015) Çin'in Kumning bölgesinde doğdu. 1945'te Endonezya'da tezini tamamladı, kardeşi ile çıkardıkları Perry Anderson New Left Review (Yeni Sol Dergi) isimli gazetede editörlük yaptı. Endonezya'dan sınır dışı edildikten sonra Tayland'da doktorasını tamamladı. 13 Aralık 2015'te Endonezya'da hayatını kaybetti (URL-1, URL-2).

Anderson Siyasi tarih ve siyaset bilimi ile ilgili çalışmalar yapmıştır. Ayrıca Güneydoğu Asya toplum ve kültürleri üzerine çalışmaları ve milliyetçilik hakkındaki çalışmaları ile tanınmaktadır (Sever, 2015, s.49). Anderson kendi çağının milliyetçilik yazarlarından farklı olarak, yazılarında Avrupa ve Amerika örnekleri dışında Asya toplumlarını da incelemiştir.

${ }^{2}$ Meçhul Asker anıtları kasten boş bırakılmış mezarlardır. Toplumsal törenler için kullanııırlar. Yazar, anıt mezarların tarihi geçmişi olmadığını vurgular. Antik Yunan'da örnekleri vardır. Ancak bu mezarlar bir sebeple gömülememiş, bilinen kişiler için hazırlanmıştır (Anderson, 1983, s. 23).
} 
Anderson 18. yüzyılın sonuna doğru ortaya çıkan milliyetçilik kavramının kendinden önceki, toplumlara yön veren kavramlarla incelenmesi gerektiği üzerinde durur. Bunlardan biri dinsel cemaatler diğeri hanedanlık mülküdür (Şekil 1). Dinsel cemaatlerin dili etkin şekilde kullandığını söyler. Kilise ayinleri için seçilen dilin, halk dili yerine Latince olarak belirlenmesini, Kuran dili Arapça'nın anlam kaybı yaşanacağı gerekçesiyle başka dillere çevrilmemesini, dilin kutsallaştırılması yönündeki adımlar olarak nitelendirir. Ancak insanlar arası etkileşimin artması ile kutsal dilin güç kaybettiğini, dinsel cemaatlerin inişe geçtiğini belirtir. Hanedanlık mülkünün ise zamanla kendisine ulusal kimlikler aradığını söyler (Anderson, 1983, s. 28-29). Bu iki kavramın milliyetçiliğin oluşmasını öncüleyen etkenler olduğunu söylese de bu kavramların yerini milliyetçiliğin aldığını söylemekten de kaçınır.

\section{Kültürel Sistemler}

\section{Dinsel Cemaat}

Hanedanlık Mülkü

Şekil 1. Milliyetçiliğin öncülü kültürel sistemler.

Millet kavramı neden bu kadar popüler oldu? Yazar bu noktada birinciliği kapitalizme verir. Kapitalizmin devrimci etkisi, üç olayla hız kazanır ve ulusal bilincin gelişmesinde önemli rol oynar (Anderson, 1983, s. 54-55) (Şekil 2).

Ulusal Bilincin Gelişmesi

Latince'nin Kendi İçinde Değişmesi $\quad$ Reform Etkisi Halk Dilinin Kullanılması

Şekil 2. Ulusal bilincin gelişmesinde etkili olan faktörler.

Latince'nin kendi içindeki değişimi bunlardan biridir. Bu dilin gitgide kullanımının azalması ve gündelik hayat dilinden uzaklaşması en az etkileyen unsur olsa da ulusal bilincin gelişiminde katkısının olduğunu söyler. Bir diğeri ise reform hareketidir. Bu noktada, Martin Luther'in ${ }^{1}$ etkisi göz ardı edilemez. Martin Luther ile başlayan ve Avrupa'da devam eden dinsel propaganda savaşında kuşkusuz kapitalist yayıncılık kazançı çıkar. Üçüncü etken olarak idarenin halk diline dönüşünü anlamak için Ingiltere örneğine yer vermek aydınlatıcı olacaktır. İngiltere'de yazınsal ve idari dilin başlangıçta Anglosakson dili olması ve 13. ve 14. yüzyılda yaşanan Norman istilası sonucu, Norman Fransızcası ile eski dilin kaynaşması Erken İngilizce dilini doğurur. 1382 yılından itibaren bu yeni dil saray dili olarak kullanılır (Şekil 3) (Anderson, 1983, s. 54-58).

\begin{tabular}{llll}
$\begin{array}{l}\text { Norman Fethi } \\
\text { Öncesi }\end{array}$ & $1220-1350$ & ERKEN ÍNGÍLİZCE & 1382 \\
\hline $\begin{array}{l}\text { Yazınsal ve idari } \\
\text { dil } \\
\text { Anglosakson }\end{array}$ & $\begin{array}{l}\text { Norman } \\
\text { Fransızcası } \\
\text { Latincenin } \\
\text { yerini aldı }\end{array}$ & $\begin{array}{l}\text { Yabancı egemen sınıfın dili ile Aglosakson } \\
\text { dilinin kaynaşması }\end{array}$ & $\begin{array}{l}\text { Erken İngilizce } \\
\text { Saray Dili olarak } \\
\text { kullanılmaya başlandı }\end{array}$ \\
\hline
\end{tabular}

Şekil 3. Halk dilinin kullanılmasında İngiltere örneğinin şematik anlatımı.

Latince'nin kullanımının azalması, reform etkisi ile kutsal kitabın çeşitli yerel dillere çevrilmesi ve idarenin halk diline dönmesi bir yana, yazar “...yeni bir üretim ve üretim

\footnotetext{
${ }^{1} 95$ maddeden oluşan "Endüljansın Kuvvetine Dair Tezler" başlıklı metnini piskoposlara göndermiş ve Wittenberg Katedrali'nin kapısına asmıştır. Bu girişimden hemen sonra metinler Almancaya çevrilmiş ve ülkenin her yanına umulmadık bir hızla yayılmıştır (Anderson, 1983, s. 54) (URL-3).
} 
ilişkileri sisteminin (kapitalizm), yeni bir iletişim teknolojisinin (matbaanın)" ulusal toplumların hayal edilebilirliğine katkısı olduğunu söylemektedir (Anderson, 1983, s. 58). Yazar, dilin ölmesi, yok olması mümkündür ancak tüm dillerin birleşmesi mümkün değildir der, ancak etkileşimler olabileceğini savunur. Bu etkileşimin oluşmasında kapitalizm ve matbaanın katkısına dikkat çeker (Anderson, 1983, s. 58-59). Böylece oluşan yayın dilleri, yayıncılığın sabitlik kazanması, Latince ile halk dili arasında yeni bir iletişim dili oluşturarak ve iktidar diline yakın olanın, diğer lehçeler üzerinde bir yere sahip olması ile ulusal bilincin temellerini attığını belirtir (Anderson, 1983, s. 59-61).

Anderson, Hayali Cemaatler kitabında, meçhul asker anıtlarını, ortak tarihin oluşturulmasını ya da sosyal, kamusal alanlarda bu tarihi anımsatacak ögelerin kullanılmasını, milliyetçiliğin kendi hedef kitlesine ulaşma yolu olarak görür. Yazılı basın ve dildeki değişimlerin, milliyetçiliğin yayılmasına zemin hazırladığına dikkat çeker. Öyleyse, Anderson'un dilin etkisi üzerinden anlattığı milliyetçilik kavramını, mimarlık üzerinden tartışmak mümkün müdür? Mimarlık milliyetçiliğin yayılması için kullanılmış bir unsur mudur? Bu bağlamda Erken Cumhuriyet Dönemi Türkiye'sinde milliyetçiliğin mimarlık aracılığıyla yayılması sorusuna, Sedad Hakkı Eldem tarafından tasarlanan, 1939 New York Fuarı Türk Evi Pavyonu projesi üzerinden cevap aranacaktır.

\section{1939 New York Fuarı Türk Pavyonu: Milli Bilinç Üzerinden Bir Değerlendirme}

1939 New York Fuarı'nda Türkiye'yi temsil eden yapının milletçilik bağlamının incelenmesine geçmeden önce pavyonun mimarisi hakkında bilgi vermek doğru olacaktır.

1939 New York Fuarı için Sedad Hakkı Eldem iki yapı tasarlar. Bunlardan biri Türk sitesi ve devlet pavyonu, diğeri ise Türk çeşmesidir (Şekil 4). Site tek katlıdır. Cephenin sağında iki katı bölüm bulunmaktadır. Eldem, hünkâr köşklerine benzeyen iki katlı bölümü sergi binasının kalesi olarak nitelendirir. Altın yaldızlı saçaklar, alçı pencereler ve kapaklar, çini işçiliği ile eski Türk evi göndermelerinin yoğun kullanıldığı söylenebilir (Eldem, 1939a, s. 153). Merkezde bulunan havuzu bir galeri çevreler ve mekânları birbirine bağlar. Eldem 1939 yılında Arkitekt dergisi için yazdığı, pavyonu anlattığı yazısında, yapının milli mimari karakterinin dikkatleri çektiğini, "Türk sitesi binası ve çeşme daha inşası esnasında şöhret bulmağa başlamış, binanın kendisine hâs milli karakteri her milletin paviyonundan fazla nazarı dikkati celbetmiştir." sözleri ile vurgular (Eldem, 1939a, s.153).

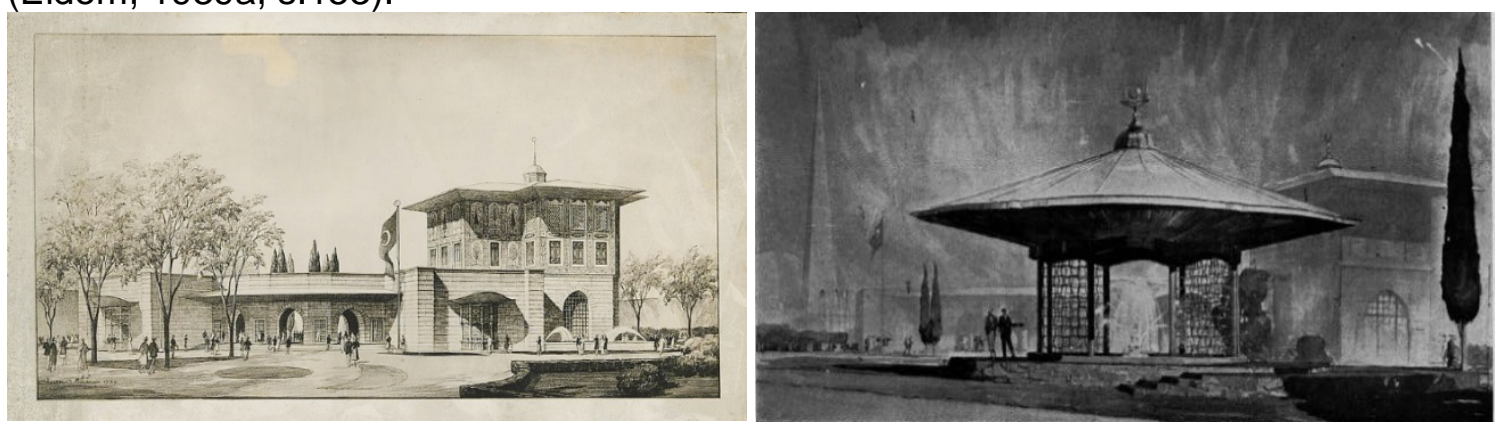

Şekil 4. 1939 New York Fuarı için tasarlanan Türk sitesi ve Türk Çeşmesi (Eldem, 1939a, s. 155) (URL-4). 

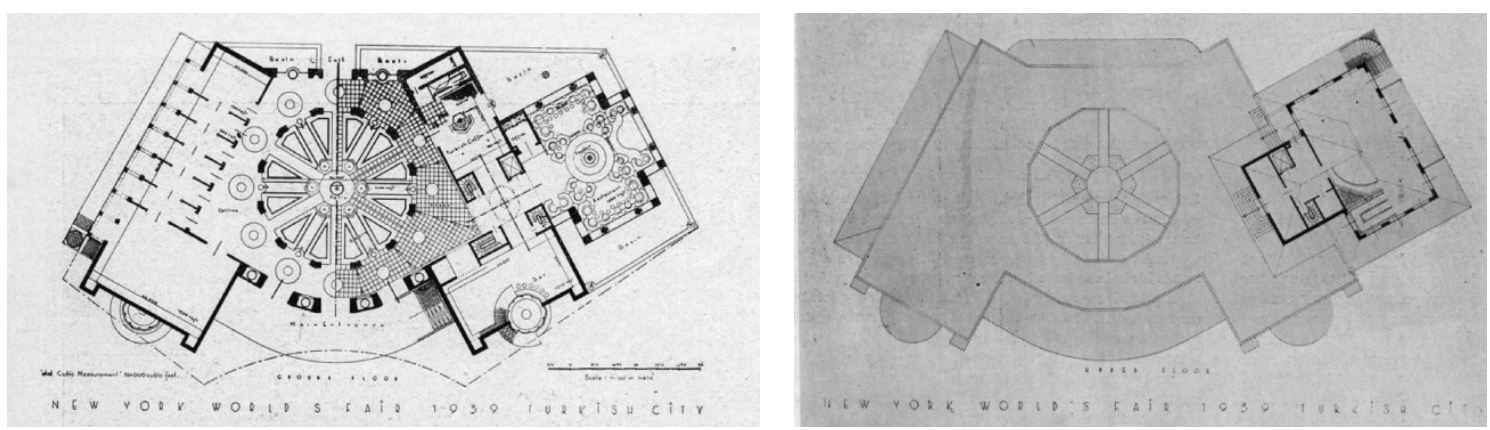

Şekil 5. 1939 New York Fuarı için tasarlanan Türk sitesi zemin kat planı (üstte) ve birinci kat planı (altta) (Eldem, 1939a, s. 154).

Fuarın teması 'Geleceğin Dünyasını Kurmak' tır. Bu temayla amaçlanan, çoğu fuarın temasından farklı olarak, bir kavramı tanıtıp yaymak değildir. Bu, dünyayı yeniden kurmaya bir davettir. Ancak Türkiye'nin, dışa karşı önyargılı tutumu ve maddi kaynaklarının yetersizliği sebebiyle, fuara katılan çoğu ülke gibi, temaya uyum sağladığı söylenemez (Tanju, 2000, s. 95). Yapı, ülkeye ait ürünlerin sergilendiği bir tanıtım alanı özelliği taşır.

Pavyon tasarımına bakıldığında Türk evi ögelerini okumak mümkündür. Bülent Tanju, Sedad Hakkı Eldem'in diğer tasarımlarında görülen Osmanlı Mimarisi soyutlamalarının aksine, pavyonda bu mimari özelliklerin bariz olarak kullanıldığına dikkat çeker (Tanju, 2000, s.104). Eldem, fuarın gerçekleştiği yıl yazdığı yapının tanıtım metninde bunun aksini söylemez. Yapıda milli mimari geleneğine ait ögelerin kullanıldığını özellikle belirtir $^{1}$. Bülent Özer'e göre Türk pavyonu, Milli Mimari akımı için bir zaferdir ancak Türkiye mimarlığı için kaçırılmış bir fırsattır (Fındıklı, 2009, s. 297).

Pavyonun tasarımında milli mimari göndermelerin bulunması, Eldem'in milli mimari hakkındaki görüşleri düşünüldüğünde tesadüf değildir. Sedad Hakkı Eldem öğrencilik yıllarından itibaren 'Türk evleri'ne ilgi duymuştur. Avrupa tecrübesi sonrasında yurda döndüğünde, Arkitekt dergisinde, Türk evinden ilham alarak tasarladığı konutları yayınlar. Bu tasarımların, modern mimari adı altında kimliksiz yapılar değil, milli mimari karaktere uygun örnekler olduğuna dikkat çeker. 1933 yılında Ernst Egli ile Milli Mimari Seminerlerini başlatır. Bu seminerler kapsamında İstanbul ve Anadolu'da unutulmuş ya da yok olmaya bırakılmış evleri ortaya çıkararak, "Türk Kültürü'nü mimarlar aracılığıyla keşfetmeyi" amaçlar (Akcan, 2009, s.47). "Milli mimari olabilir mi değil, olmalıdır..." (Eldem, 1939b, s.221).

Eldem'e göre Türkiye'ye modernizmin gelişi bir intiyaçtan kaynaklanır. Yeni kurulan ülkenin, yeni başkenti Ankara için yabancı mimarlar davet edilir. Bu süreçte kendi kültürlerini yansıttıkları tasarımlar ortaya çıkar. İhtiyaçlar sebebi ile stil arayışı ikinci plandadır. 1930'lu yıllarda ise artık milli mimari ile ilgilenmek gereklidir (Eldem, 1939b, s. 221; Ulubay, 2019, s. 389).

Sedad Hakkı Eldem eski Türk evlerinin yeni modern mimarlığa yol gösterdiğini her fırsatta dile getirir ${ }^{2}$ (Akcan, 2009, s. 48, Bozdoğan, 2009, s. 19). Benzer şekilde Josep

\footnotetext{
1 "Mimar, binada eski Türk mimarisinde olduğu gibi - suya hususî bir ehemmiyet vermiştir, havuzlar, havuz taşları, sebiller ve bunların geceleri projektörlerle ziya oyunları yapması, binanın dekoratif unsurları meyanındadır. Site Türk binasından maada site önündeki meydanın ortasında Nevyork belediyesine hediye olarak bir çeşme yapılmıştır. Bu çeşme de Türk karakterinde düşünülmüştür..." (Eldem, 1939a, s.153-154)

2 "...Ehemmiyet verdiğim taraf, eski Türk evinin bugünkü modern ev telakkilerine şaşılacak derecede yakın olmasıdır. Bol pencereli ve aydınlık olduğuna daha önce işaret ettim. Planında serbestlik, konfora gösterişten fazla ehemmiyet verilmesi, malzeme icaplarına daima sadık kalınması, bol taraçalar (hayatlar) ile bahçe ve avlu, yani tabiat ile evin sıkı
} 
Lluis Sert ${ }^{1}$ ve Ernesto Peresutti ${ }^{2}$ de modern mimarlığın Kuzey ülkelerinin icadı olsa da, esin kaynağının kendi milli mimarileri - İspanyol ve İtalyan- olduğunu, Akdeniz mimarlığı ile benzerliğine işaret ederek anlatır (Bozdoğan, 2009, s.19). Mimarlar bu söylemleri ile milliyetçi politikaların egemen olduğu o yıllarda kendi toplumlarının yerel mimari özelliklerini sıralayarak, dönemin mimari üslubu olan modernizmin zaten yerel olduğunu anlatmaya çalışır.

Ortak geçmiş oluşturmanın milli bilincin oluşumuna katkı sağladığını söylemiştik. Celal Esad Arseven de bunu mimarlık aracılığıyla yapar. Türk mimari kültürünü Arap ve İran mimarisinden farklı adlandırılması fikrini, "... Türk sanat eserleri adaletsizce Araplara ya da Iranlılara atfedilmiştir! Sanki Türkler gibi göçebe bir halkın sanatı olmayacağı varsayılır" sözleriyle dile getirir. Arseven, göçebe kültüründe kullanılan çadır ile Anadolu evleri arasında benzerlikler kurar. Ernest Egli de benzer şekilde antik Türk insanlarının kullandığı Türk evi ile Osmanlı dönemi konut mimarisinin benzerliklerine dikkat çeker ${ }^{3}$ (Akcan, 2009, s.48-49).

Sedad Hakkı Eldem ise, farklı bir tarihe dayandırsa da benzer söylemlerde bulunur ve Türk evinin Osmanlı Döneminde ortaya çıktığı teorisini ortaya atar. Türk evini, Arap ve İran evinden ayrı tutması ve Balkanlardaki konutları örnek olarak göstermesi milli tarih yazımını destekler niteliktedir (Akcan, 2009, s. 50). Selen Morkoç, tarihçi Eric Hobsbawm'ın gelenek icadı teorisini Eldem'in Türk evi çalışmaları üzerinden okur. “...Eldem'in Türk evi olarak adlandırdığı Osmanlı ev şemaları üzerine yoğunlaşan belgelendirme ve tasarım eşitlemelerini birer gelenek icadı olarak yorumlamak mümkündür" der (Morkoç, 2009, s.290). Morkoç'a göre milli gelenek icadı Eldem ile birlikte mimarlık üzerinden kendini gösterir. Esra Akcan ise, Osmanlı Döneminde kullanılan konutların Erken Cumhuriyet Dönemi ile birlikte Türk evi olarak adlandırımasını tarihin milliyetçi ideallere uyarlanması olarak yorumlar. Osmanlı döneminde var olan etnik çeşitliliğe rağmen hepsini kapsayacak, "Türk" kavramının kullanıldığına dikkat çeker. Bu hareket, milli bilinç oluşturarak, var olan konutların korunmasına katkı sağlasa da etnik zenginliğin göz ardı edilmesine neden olduğunu savunur (Akcan, 2009, s. 51-52).

\section{Değerlendirme ve Sonuç}

Benedict Anderson, Hayali Cemaatler Milliyetçiliğin Kökenleri ve Yayılması kitabında milliyetçilik kavramını yeniden tanımlamıştır. 1978-79 yılları arasında yaşanan savaş, siyasi ve toplumsal değişimler, yeni kurulan dünya düzeni yazarı bu tanım üzerine düşünmeye itmiştir. Milliyetçilik, milleti oluşturmada önemli bir kavramdır. Kitapta yer alan Ulusal Bilincin Kökenleri metninde yazar, milli bilincin aktarılması konusunda dil,

\footnotetext{
sıkı bağlanması... Bunların hepsini eski Türk evlerinde buluruz... Le Corbusier de Türkiye'den çok ilham almıştır..." (Akcan, 2009, s. 48, Bozdoğan, 2009, s. 19).

1 “... Eğer Akdeniz'in vernaküler yapı örneklerini inceleyip, bunları modern mimarlığın en iyi eserleriyle kıyaslarsak, aralarında pek çok ortak özellik görmeden edemeyiz; detaylarda değil, bir mimari esere ruhunu veren 'değişmez öğelerde'dir bu ortaklık. O halde modern mimarlığa neden 'Alman' bir mimarlık denmiştir? Modern mimarlık, teknik açıdan büyük ölçüde Kuzey memleketlerinin icadı olabilir ama bu yeni mimarlığı etkileyen ruh, üslupsuz bir Akdeniz mimarlığıdır. Modern mimarlık Akdeniz'in saf, geleneksel formlarına dönüştür. Latin denizinin bir başka zaferidir bu!..." (Bozdoğan, 2009, s.19).

2 "... Etrafa baktığımızda, her yerde bir beyaz duvarlar mimarisi, dikdörtgen veya kare, yatay veya dikey; bir dolulukboşluk, renkler ve formlar, geometri ve proporsiyon mimarisi... Bunlar Akdeniz mimarisinin karakteristik özelliğidir; insan eseri formlarla doğanın renk ve formlarını kaynaştırarak zamana kafa tutan piramitleri inşa etmiş, bir Roma su kemerinin ritmini ya da Akropol'ün senfonisini bestelemiş olan Akdeniz ruhudur. İşte hepsi burada: Biskra'nın evleri, Libya'nın evleri, Capri'nin evleri... Gropius, Le Corbusier, Mies van der Rohe tarafından keşfedilip, kuzey kökenli bir 20.yüzyıl icadıymış gibi yutturulan bir miras..." (Bozdoğan, 2009, s.19).

3 Egli'ye göre göçebe olarak yaşayan Türkler önce alanlarını sınırlandırmış, bahçe kullanımına ayrılan alan içinde çadırlarda yaşamıştır. Çadırlar, pavilyonlara; pavilyonlar köşklere; köşkler, çıkmalı köşklere dönüşmüştür. Son olarak da bahçenin üstü örtülerek bu mekan sofaya evrilmiştir (Akcan, 2009, s.48-49).
} 
kapitalizm ve matbaanın önemine dikkat çeker. Yazara göre milliyetçiliğin yayılmasında dil ve iletişim önemli bir etkendir.

Yeni ulus inşaalarında mimarlık, milliyetçi tavırdan etkilenmiştir. Milli bilincin yayılmasında iletişim bir etkense, iletişim yolu olarak mimarlık ve mimari ifadeler bu kavramın yayılmasında Anderson'un teorisindeki dilin rolünü üstlenir. Bu bağlamda, Türkiye Cumhuriyeti'nin başkenti olarak Ankara'nın belirlenmesi ile kentin mimarisinde köklü değişimler yaşanması ve sonraki yıllarda milli mimariye yönelim, dünya fuarlarında sıklıkla milli mimari ögelerin kullanımı buna örnek gösterilebilir. Türkiye'de Erken Cumhuriyet Dönemi'nde, milli bilincin aktarımını sağlayan etkenlerden birinin mimarlık olduğunu söylemek yanlış olmayacaktır.

Eldem'in öğrencilik yıllarındaki milli mimariye olan ilgisi, sonraki yıllarda kendisinin deyimi ile zorunluluk olmuştur. 1930'lu yıllarda başlayan 1976'ya kadar devam eden Milli Mimari Seminerleri, konut çalışmaları, 1939 yılı New York Fuarı Türk Pavyonu tasarımı ve sonradan Eldem'in fuarı anlatmak için yazdığı yazıları mimarlık ile milli bilincin oluşturulması yönünde atılan adımlardır.

Erken Cumhuriyet Dönemi mimarları modern olanı millileştirirken Türk kökenlerini Osmanlı'ya, Hititlere, Orta Asya'ya dayandırır. Anderson'un işaret ettiği milli bilincin gelişiminde ortak geçmiş yaratma olgusu, mimaride kendini, yeni mimari üsluplarda, geleneksel mimari ögeleri arama ile ve bu ögelerden yola çıkma yöntemi ile gösterir. Bu kavram yeni'nin, eski'den beslenmesi olarak karşımıza çıkar.

\section{Kaynaklar}

Akcan, Esra, "Eldem, Arseven, Egli ve "Türk Evi" Tezinin Algılanan Nesnelliği", Sedad Hakkı Eldem II Retrospektif, 1. B., Ofset Yapımevi, İstanbul 2009, s. 47-53.

Milli Mimari Meselesi, Arkitekt Dergisi, 1939/ 1939-09-10 (105-106), s. 220-223.

Anderson, Benedict, Hayali Cemaatler Milliyetçiliğin Kökenleri ve Yayılması, Çev: İskender Savaşır, Metis Yayıncılık, İstanbul 1983.

Bozdoğan, Sibel, Modernizm ve Ulusun İnşası, Metis Yayınları, İstanbul 2002.

Eldem, Sedad Hakkı, "1939 New York Sergisinde Türk Pavyon Projesi", Arkitekt Dergisi, 1939a/ 1939-07-08 (103-104), s. 153-155.

Eldem, Sedad Hakkı, "Milli Mimari Meselesi", Arkitekt Dergisi, 1939b/ 09-10, s. 220223.

Fındıklı, Erhan Berat, "Mimarlık Tarihi Yazımı ve Sedad Hakkı Eldem'in Bağlamsallaştırılması", Sedad Hakkı Eldem II Retrospektif, 1. B., Ofset Yapımevi, İstanbul 2009, s. 297-308

Hobsbawm, Eric, J., Milletler ve Milliyetçilik, Çev: Osman Akınhay, Ayrıntı yayınları, İstanbul 1995.

Morkoç, Selen B., "Henüz Bitmemiş Bir Proje: Türk Evi", Sedad Hakkı Eldem II Retrospektif, 1. B., Ofset Yapımevi, İstanbul 2009, s.290-296

Sever, Merin, "Ulus İnşası ile Milliyetçilik Literatürünün İnşası Arasında Benedict Anderson", Evrensel Kültür Dergisi, 2015/Ekim, s. 49-53. 
Sönmez, Cahide, "Yarının Dünyası'nda Türkiye: 1939 New York Dünya Sergisi”, Journal of Modern Turkish History Studies, 2015/Güz, s.236-332.

Tanju, Bülent, "1939 New York Dünya Fuarı Üzerine Notlar", Arredamento Mimarlık, 2000/10, s.94-105.

Ulubay, Serhat. "Erken Cumhuriyet Dönemi Türkiyesi'nde "Moderni Millileştirme" Çabasının Sorgulanması", Kent Akademisi, cilt 12, sayı 2, 2019, s. 387-396.

URL-1: https://tr.wikipedia.org/wiki/Benedict_Anderson Erişim Tarihi: 24.10.2020

URL-2: https://www.birgun.net/haber/benedict-anderson-hayali-cemaatler-in-izinde-birasya-uzmani-98333 Erişim Tarihi: 24.10.2020

URL-3: https://tr.wikipedia.org/wiki/Martin_Luther Erişim Tarihi: 22.10.2020

URL-4:

https://upload.wikimedia.org/wikipedia/commons/5/52/Sketches_by_Sedad_Hakk\%C4 \%B1_Eldem_\%2817084856712\%29.jpg Erişim Tarihi: 26.12.2020 